\title{
Use of a strip-clip technique to maintain transposition of a vertebral artery in microvascular decompression surgery
}

\author{
Andreas Raabe • Alongkorn Jaiimsin • Volker Seifert • \\ Jürgen Beck
}

Received: 16 August 2011 / Accepted: 21 September 2011 /Published online: 8 October 2011

(C) Springer-Verlag 2011

\section{Dear Editor,}

Microvascular decompression (MVD) has become an effective treatment of trigeminal $[3,5]$ or glossopharyngeal neuralgia [7, 10] and hemifacial spasm [2,9]. During surgery, a soft implant is commonly used to relieve the nerve or the medulla from the arterial pulsatile pressure. However, an implant may fail when the offending vessel, such as the vertebral artery (VA) or basilar artery (BA), is large and ectatic. We report a recently used alternative stripclip technique that can be easily applied to a large vessel such as an ectatic VA.

The patient was a 46-year-old man with malignant arterial hypertension, despite having a seven-drug therapy. Magnetic resonance imaging revealed compression of the left rostral ventrolateral medulla (RVLM) caused by the left VA. Given these findings and the failed multidrug therapy in this young patient, MVD of the RVLM was proposed as a controversial last resort treatment.

The patient underwent MVD via a left-sided far lateral approach. The VA was exposed at the site of left RVLM compression and dissected off the brain stem. A $5 \times 30-\mathrm{mm}$

A. Raabe $\cdot$ V. Seifert $\cdot$ J. Beck

Department of Neurosurgery, Neurocenter,

Johann Wolfgang Goethe University,

Frankfurt am Main, Germany

\section{A. Jaiimsin}

Department of Surgery, Neurosurgical Division, Bangkok

Metropolitan Administration Medical College and Vajira Hospital, Bangkok, Thailand

\section{A. Raabe $(\bowtie)$}

Bern University Hospital, Department of Neurosurgery, c/o Publication Office, Susan Wieting,

3010 Bern, Switzerland

e-mail: susan.wieting@insel.ch strip of equine collagen sheet (Vostra, Aachen, Germany) was prepared and a small hole was cut into both ends of the strip. The strip was wrapped around the VA to create a sling. The ends were brought together and a straight minianeurysm clip (Aesculap, Tuttlingen, Germany) was threaded through both holes. The clip was then moved close to the petrous dura to determine the best position of the sling to provide gentle traction on the VA. This position was marked. A small dissector was used to create a hole in the petrous dura at that position. The strip-clip was moved to this position again and the clip was slightly opened to clip the dura with one clip branch in the hole previously created. The position of the VA was checked to make sure that traction on perforating arteries was avoided but the medulla was decompressed from the VA. Once the position of the clip was correct, the clip was moved into the dural hole and fixed (Fig. 1). At the time of discharge, the hypertension of the patient was controlled by a three-drug therapy.

Repositioning of the VA may be considered as a last resort treatment for multidrug-resistant, severe, idiopathic arterial hypertension with significant compression of the RVLM $[4,6]$. This approach is difficult because of the perforators arising from the VA to the medulla and the tendency of the VA to slip back to the original position. Interposing material between the VA and the medulla may not provide adequate decompression and result in a severe increase in arterial blood pressure during surgery. To overcome these difficulties, we found it useful to create a sling that could be wrapped around the VA and adjusted in length to fit variable distances. Creating a hole in both ends of the strip enables the surgeon to use a conventional clip or a mini-clip to affix the sling to the dura mater as required and avoids unnecessary manipulations to maintain distance between the VA and RVLM. This technique could also be 
Fig. 1 Schematic drawing (left) and intraoperative photograph (right) illustrating the various steps of the strip-clip technique for repositioning the VA. After opening of the dura, the situs shows the VA compressing the left RVLM (a). A strip of equine collagen dura substitute was trimmed and holes were cut at both sides (asterisk). The VA is elevated at the site of maximum compression and the strip was moved between the VA and the medulla (b) to wrap around the VA with both holes lateral to the VA. The clip was then threaded into the holes (c). The clip tightens the sling and a point at the petrous dura was chosen where the VA is pulled $1 \mathrm{~mm}$ off the RVLM. This point was marked, and a dissector was used to create a hole into the petrous dura. Then the clip with the sling was moved to this point and one branch of the clip was moved into the dural hole and fixed (d)
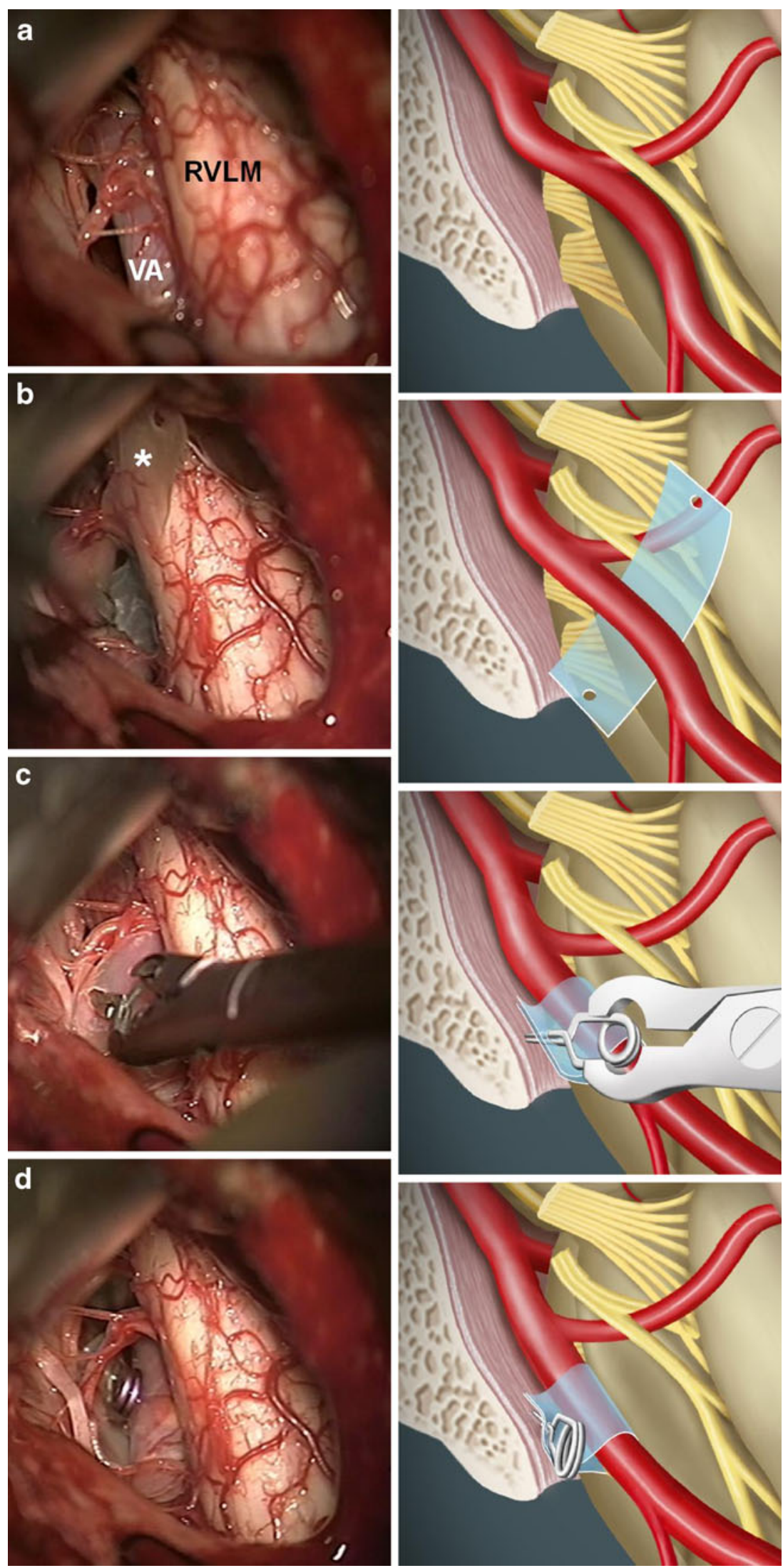
used in other neurovascular compression syndromes caused by the VA where it seems difficult to provide a durable repositioning of this large artery. Compared with other sling techniques $[1,8]$, this method is a straightforward manoeuvre to achieve a contact-free transposition without any interposed additional material.

Acknowledgements The authors received editing support for the final version from Susan Wieting, Bern University Hospital, Department of Neurosurgery, Bern, Switzerland.

Financial disclosure No funding was received for this article.

\section{Conflicts of interest None.}

\section{References}

1. Attabib N, Kaufmann AM (2007) Use of fenestrated aneurysm clips in microvascular decompression surgery. Technical note and case series. J Neurosurg 106:929-931

2. Auger RG, Piepgras DG, Laws ER Jr, Miller RH (1981) Microvascular decompression of the facial nerve for hemifacial spasm: clinical and electrophysiologic observations. Neurology $31: 346-350$

3. Barker FG, Jannetta PJ, Bissonette DJ, Jho HD (1997) Trigeminal numbness and tic relief after microvascular decompression for typical trigeminal neuralgia. Neurosurgery 40:39-45

4. Fein JM, Frishman W (1980) Neurogenic hypertension related to vascular compression of the lateral medulla. Neurosurgery 6:615622

5. Jannetta PJ (1967) Arterial compression of the trigeminal nerve at the pons in patients with trigeminal neuralgia. J Neurosurg 26 (Suppl):62

6. Jannetta PJ, Segal R, Wolfson SK Jr (1985) Neurogenic hypertension: etiology and surgical treatment. I. Observations in 53 patients. Ann Surg 201:391-398

7. Laha RK, Jannetta PJ (1977) Glossopharyngeal neuralgia. J Neurosurg 47:316-320

8. Melvill RL, Baxter BL (1996) A tentorial sling in microvascular decompression for trigeminal neuralgia. Technical note. J Neurosurg 84:127-128

9. Samii M, Gunther T, Iaconetta G, Muehling M, Vorkapic P, Samii A (2002) Microvascular decompression to treat hemifacial spasm: long-term results for a consecutive series of 143 patients. Neurosurgery 50:712-718

10. Sampson JH, Grossi PM, Asaoka K, Fukushima T (2004) Microvascular decompression for glossopharyngeal neuralgia: long-term effectiveness and complication avoidance. Neurosurgery 54:884-889 